Journal of Social Sciences 3 (3): 143-150, 2007

ISSN 1549-3652

(C) 2007 Science Publications

\title{
HIV/AIDS Prevention Knowledge among Youth in Cape Town, South Africa
}

\author{
${ }^{1}$ Kermyt G. Anderson and ${ }^{2}$ Ann M. Beutel \\ ${ }^{1}$ Department of Anthropology, University of Oklahoma, Norman, OK, USA \\ ${ }^{2}$ Department of Sociology, University of Oklahoma, Norman, OK, USA
}

\begin{abstract}
HIV/AIDS knowledge is an important component of HIV/AIDS risk prevention strategies that may influence engagement in high risk behavior. This paper examines HIV/AIDS prevention knowledge among a representative sample of 4,174 youth living in Cape Town, South Africa. Data come from the Cape Area Panel Study (CAPS), and include black, coloured, and white respondents ages 14-22. Using an open-ended question, respondents were asked to name ways people can protect themselves from HIV/AIDS infection. Nearly everyone could name at least one method of preventing HIV infection, and respondents named two methods on average. Condoms, abstinence, and limiting the number of sexual partners/having only one sexual partner were the most frequently named prevention methods. Multivariate analysis was used to analyze correlates of specific forms of HIV/AIDS prevention, as well as the total number of prevention methods named by each respondent. Having had sex, highest grade completed, and race were the most commonly significant correlates across models. Race interaction terms were also significant, suggesting that the significance of HIV/AIDS knowledge correlates varies across racial groups. Overall, the results suggest that more depth of knowledge about HIV/AIDS is needed among South African youth to ensure proper protection from the disease, and that HIV/AIDS education might be more successful if tailored to specific racial/ethnic groups.
\end{abstract}

Key words: disease; education; adolescents; race; condoms INTRODUCTION

Considerable attention has been paid in social science, medical, and public health research to the factors influencing HIV/AIDS risk behaviours. Many models of health behaviour, such as the AIDS Risk Reduction Model, the Information-MotivationBehavioural Skills Model, and the Health Belief Model, posit that knowledge about the facts of HIV/AIDS transmission will lead to more preventive behaviours and fewer risky behaviours ${ }^{[1-3]}$. HIV/AIDS knowledge among young people is of great concern in South Africa, where HIV prevalence among 15-24 year-olds is $10.3 \%{ }^{[4]}$. As in many other less developed countries, the primary method of HIV/AIDS transmission in South Africa is heterosexual intercourse ${ }^{[5]}$. Numerous HIV/AIDS education and prevention programmes in South Africa have operated under the premise that educating youth and other high-risk groups is key to reducing the spread of the disease ${ }^{[6]}$. For example, the ABC campaign, advising people to Abstain, Be faithful, and use a Condom, has received widespread dissemination in South Africa. Yet many questions remain about the level of HIV/AIDS knowledge among
South African youth and their ability and willingness to make use of that knowledge to reduce HIV/AIDS risk ${ }^{[7-}$ 9]. In a country with high HIV prevalence, understanding the level of HIV/AIDS prevention knowledge and the factors influencing this knowledge could have important and far-reaching implications on a public health phenomenon that threatens to negatively impact numerous aspects of society, ranging from health and mortality to economic productivity. This paper examines HIV/AIDS prevention knowledge and its correlates for a representative sample of youth in Cape Town, South Africa. It also examines whether the correlates of HIV/AIDS knowledge operate differently by race, an important social category in South Africa.

HIV/AIDS knowledge: Recent studies among youth in South Africa and other African countries have found at least moderate levels of knowledge about HIV/AIDS, but important gaps in HIV/AIDS knowledge remain $^{[4,7,10-13]}$. Condoms, abstinence, and monogamy or limiting the number of partners are the most frequently named methods of preventing HIV/AIDS, although condoms are mentioned far more often than the other methods ${ }^{[14-15]}$.

Corresponding address: $\quad$ Kermyt G. Anderson, Department of Anthropology, 521 Dale Hall Tower, 455 West Lindsey, University of Oklahoma, Norman, OK 73019, USA 
The relationship between HIV/AIDS knowledge and behaviours has been debated. Engagement in high risk HIV/AIDS behaviours (e.g., multiple sex partners, inconsistent condom use) despite knowledge about HIV/AIDS has been found in some studies of youth in Africa, but other studies have found positive associations between HIV/AIDS knowledge and HIV/AIDS prevention behaviours ${ }^{[8,9,11,16-18]}$. Further, recent evidence on the sexual behaviours of young South Africans indicates that preventive behaviours (condom use and fewer sexual partners) have increased $^{[15,19-20]}$. This suggests that campaigns to increase knowledge about HIV/AIDS may be having an effect on behaviours, and underscores the importance of assessing knowledge about HIV/AIDS prevention.

Besides risk behaviours, a number of other factors may be correlated with level of HIV/AIDS knowledge among young people in Africa. Young people who know someone living with HIV/AIDS or who died of the disease may be more knowledgeable about the disease than others ${ }^{[10]}$. Youth who have completed more grades in school may have received more information about HIV/AIDS than others, and a positive association between educational attainment and HIV/AIDS knowledge has been found in some African studies ${ }^{[7,10]}$. School enrollment status may be important as well because youth who are in school may have more current exposure to HIV/AIDS education and prevention methods than youth who are not. Educational attainment and school enrollment status also may serve as proxies for socioeconomic status. In addition, we might expect older youth to be more knowledgeable about HIV/AIDS prevention than younger youth ${ }^{[11,16,21]}$, but some studies have found no association between age and HIV/AIDS knowledge ${ }^{[7]}$. Finally, evidence about the relationship between gender and HIV/AIDS knowledge is also mixed, with studies finding no gender effects, effects favoring males, or effects favoring females ${ }^{[7,11,16,22]}$.

Race and HIV/AIDS knowledge: Although race has been, and remains, a major factor in South African social life, relatively little attention has been paid to racial or ethnic differences in HIV/AIDS knowledge. Race (population group) is particularly important in South Africa, in part because of the legacy of apartheid, the former policy of strict racial segregation. Under apartheid, coloureds (mixed race) and Indians (Asians) were moderately disadvantaged relative to whites (European ancestry), while blacks (Africans) were severely disadvantaged. Although apartheid laws were repealed by the early 1990s, racial inequality and de facto segregation still exist in South Africa, contributing to continued economic and health inequalities by race ${ }^{[23,24]}$. HIV prevalence varies by race. Among South African ages 15 to 24, 12.3\% of blacks, $1.7 \%$ of coloureds, $0.3 \%$ of whites, and $0.8 \%$ of Indians are HIV positive ${ }^{[4]}$. Studies in South Africa that have used multi-race samples have found white and Asian youth are more knowledgeable about HIV/AIDS than black and coloured youth ${ }^{[22,25]}$. However, most studies in South Africa have used single race samples (typically black). In order to better understand and redress racial health inequalities, it is important to consider whether there is racial variation in the correlates of HIV/AIDS knowledge.

Hypotheses: We predict that current school enrollment, grade attainment, knowing somebody with HIV or who died of AIDS, and having ever had sex (i.e., being sexually experienced) will be key correlates of HIV/AIDS knowledge. We expect higher values of each of these four variables to be associated with higher levels of HIV/AIDS prevention knowledge. Background variables in our study are age, race, and gender. Age may be positively associated with HIV/AIDS knowledge, and blacks may have less HIV/AIDS knowledge than coloureds and whites. In view of the mixed findings of previous studies, we make no specific predictions about the possible association between gender and HIV/AIDS knowledge.

\section{MATERIALS AND METHODS}

Data: We used data from Wave I of the Cape Area Panel Study (CAPS), a new study of youth and their families living in Cape Town, the second largest city in South Africa ${ }^{26]}$. CAPS is a joint project of the University of Cape Town and the University of Michigan, operating under the approval of human subject review boards at both universities. Written consent was obtained from all respondents, and written parental consent was obtained for respondents under age 18. Both authors of this paper were involved in the design and implementation of the Wave I study.

CAPS used a two-stage probability sampling design. The first stage sampled 440 Census Enumeration Areas (EAs) and the second stage sampled 25 households (in both formal and informal housing areas) within each selected EA. Black and white households were oversampled with the goal of obtaining roughly equal numbers of black, coloured, and white youth. Upon recruitment into the survey, the household questionnaire was administered to the person most knowledgeable about the household. Full-length youth questionnaires were given separately to up to three young people (ages 14 to 22) in each household. (For further details about the design of CAPS, see ${ }^{[26]}$.)

The 2002 baseline wave of CAPS included 5,256 households containing 22,631 residents (42.3\% black, $43.7 \%$ coloured, and $14.1 \%$ white). Detailed interviews were conducted with 4,752 young people (44.7\% black, 39.5\% coloured, and $15.7 \%$ white). The response rates for the youth questionnaire (conditional on household participation) were high for all racial groups, ranging from $93.0 \%$ for blacks to $86.0 \%$ for whites. 
Measures: A number of measures from the CAPS youth questionnaire were used to test our hypotheses. They included the following:

- HIV/AIDS prevention knowledge: We used an open-ended question to solicit knowledge of HIV/AIDS prevention. Open-ended questions tend to elicit fewer HIV/AIDS prevention methods compared to close-ended questions, and may better reflect the actual information youth retain and are able to use $\mathrm{e}^{[7]}$. The question in CAPS asked: "How can people protect themselves from getting infected with HIV/AIDS?” Respondents answered this question without prompting, and multiple responses were allowed. Responses were coded by the interviewer into the following categories, which were not seen by the respondents: "Abstain from sex," "Non-penetrative sex/thigh," "Always use condoms," "Limit number of sex partners," "Have only one sex partner," "Avoid sex workers," "Use sterilised needles," and "Require partner to take blood test." For the current analysis, "limit number of sex partners" and "have only one sex partner" were collapsed into a single variable. Each of these responses was a separate dichotomous variable, indicating whether or not the respondent mentioned that particular prevention method. In addition, a new variable counting the number of correct ways to prevent HIV infection the respondent reported was created, which ranged from zero to seven.

- Participation in HIV/AIDS risk behaviours: This was measured with a question asking respondents whether they had ever had sexual intercourse, which was coded dichotomously (yes $=1$ and no $=0$ ).

- Personal experience with HIV/AIDS: This was

- measured by a dichotomous variable collapsing two separate questions asking whether the respondent knew anybody with HIV/AIDS or who had died of HIV/AIDS.

*Schooling: School enrollment was measured by a dichotomous variable indicating whether the respondent was in school or university at the time of the survey, while educational attainment was measured by the highest grade the respondent had completed.

*Background variables: Respondent's age was coded in years and gender was coded 1 for males and 0 for females. Race was coded using dummy variables for coloureds and whites, with blacks as the reference category. (Only 27 respondents, $0.6 \%$ of the entire sample, belonged to another racial group; these were dropped from the analysis.)

Analysis: After deleting missing cases as well as "don't know" responses, the final sample for analysis was 4,174. We restricted multivariate analysis to five measures of HIV/AIDS prevention knowledge. Of the individual ways to prevent HIV infection named by respondents, four were mentioned by at least $10 \%$ of respondents: always use a condom, abstain from sex, limit the number of sex partners/have only one partner, and use sterilised needles. Each of these was modeled as a dependent variable, using multivariate logistic regression. (The other methods of HIV prevention were mentioned by less than $10 \%$ of respondents. Because they exhibit relatively little variation across respondents, these models are not included here, but are available from the authors upon request.) The total number of ways each respondent named to prevent HIV infection was analyzed using multivariate ordinary least squares regression.

Our models include interaction terms between race and each of the four key correlates (current school enrollment, highest grade completed, ever had sex, and know somebody with or who died of HIV/AIDS). (The results of baseline models containing no interaction terms and models done separately by race are available from the authors.) The interaction terms allowed us to examine whether the relationship between each key correlate and HIV/AIDS prevention knowledge varied by race. In preliminary models every possible race interaction term was added, but in the final models interaction terms that were completely non-significant were dropped. (Interaction terms between gender and the four key correlates were also examined but were not significant, suggesting that the relationships between the key correlates and HIV/AIDS prevention knowledge do not vary by gender.

Analyses were performed in Stata/SE 9.1, using the "svy" commands to adjust standard errors to account for the multistage survey design. Results from logistic regression analyses are presented as odds ratios. When weighted for oversampling of blacks and whites and non-response of households and youth, the results are representative of metropolitan Cape Town.

\section{RESULTS}

Summary statistics (means or percentages) for the variables used in the analysis are presented by race in Table 1. Results from ANOVAs are also included in the table and indicate statistically significant variation across racial groups of $p<.05$ or less for almost all measures. The respondents were about 18 years old on average and just under half the sample was male. Although most respondents were enrolled in school at the time of the study, whites were most likely to be in school and coloureds were least likely. The average respondent completed 9.5 years of schooling, with whites completing more grades than blacks or coloureds. Approximately $41 \%$ of the sample had ever had sex, with a majority of blacks being sexually experienced (61.2\%) compared to roughly a third or less of coloureds and whites. Finally, more blacks (40.2\%) knew somebody with or who died of HIV/AIDS than coloureds (20.2\%) and whites (13.6\%). 
Table 1: Descriptive statistics for youth, by race, 2002 Cape Area Panel Study, Cape Town, South Africa

\begin{tabular}{|c|c|c|c|c|c|c|c|c|c|c|}
\hline & \multicolumn{2}{|c|}{ Total } & \multicolumn{2}{|c|}{ Black } & \multicolumn{2}{|c|}{ Coloured } & \multicolumn{2}{|c|}{ White } & \multirow[b]{2}{*}{$\mathrm{F}$} & \multirow[b]{2}{*}{$\mathrm{p}$} \\
\hline & Mean & $\begin{array}{l}\text { std. } \\
\text { error }\end{array}$ & Mean & $\begin{array}{l}\text { std. } \\
\text { error }\end{array}$ & Mean & $\begin{array}{l}\text { std. } \\
\text { error }\end{array}$ & Mean & $\begin{array}{l}\text { std. } \\
\text { error }\end{array}$ & & \\
\hline Age & 17.904 & 0.048 & 18.099 & 0.064 & 17.793 & 0.066 & 17.916 & 0.144 & 5.54 & 0.004 \\
\hline Male & 0.479 & 0.008 & 0.453 & 0.012 & 0.489 & 0.013 & 0.490 & 0.020 & 2.48 & 0.085 \\
\hline Currently in school & 0.648 & 0.010 & 0.667 & 0.014 & 0.564 & 0.015 & 0.851 & 0.019 & 69.02 & 0.000 \\
\hline Highest grade completed & 9.512 & 0.053 & 8.925 & 0.066 & 9.421 & 0.077 & 10.617 & 0.116 & 82.23 & 0.000 \\
\hline prevent HIV/AIDS & 1.862 & 0.023 & 1.543 & 0.025 & 1.866 & 0.028 & 2.318 & 0.073 & 70.75 & 0.000 \\
\hline Ever had sex & 0.414 & 0.010 & 0.612 & 0.014 & 0.346 & 0.014 & 0.307 & 0.026 & 114.19 & 0.000 \\
\hline $\begin{array}{l}\text { died of HIV/AIDS } \\
\text { Ways named to protect from } \\
\text { HIV/AIDS infection }\end{array}$ & 0.246 & 0.010 & 0.402 & 0.019 & 0.202 & 0.013 & 0.136 & 0.017 & 60.55 & 0.000 \\
\hline Always use condoms & 0.888 & 0.007 & 0.919 & 0.010 & 0.883 & 0.010 & 0.856 & 0.020 & 5.69 & 0.004 \\
\hline $\begin{array}{l}\text { Abstain from sex } \\
\text { Limit number of sex }\end{array}$ & 0.465 & 0.012 & 0.372 & 0.016 & 0.483 & 0.017 & 0.553 & 0.026 & 21.68 & 0.000 \\
\hline $\begin{array}{l}\text { partners / have only one sex } \\
\text { partner }\end{array}$ & 0.233 & 0.010 & 0.181 & 0.012 & 0.229 & 0.013 & 0.319 & 0.030 & 10.9 & 0.000 \\
\hline $\begin{array}{l}\text { Use sterilised needles } \\
\text { Require partner to take }\end{array}$ & 0.108 & 0.007 & 0.022 & 0.005 & 0.117 & 0.010 & 0.207 & 0.024 & 67.14 & 0.000 \\
\hline blood test & 0.082 & 0.006 & 0.024 & 0.004 & 0.075 & 0.008 & 0.187 & 0.022 & 38.63 & 0.000 \\
\hline Avoid sex workers & 0.033 & 0.004 & 0.010 & 0.002 & 0.029 & 0.005 & 0.079 & 0.015 & 15.24 & 0.000 \\
\hline Non-penetrative sex/thigh & 0.011 & 0.002 & 0.004 & 0.002 & 0.008 & 0.002 & 0.030 & 0.009 & 4.65 & 0.010 \\
\hline $\mathrm{N}$ & 4,174 & & 1,894 & & 1,739 & & 541 & & & \\
\hline
\end{tabular}

Table 2: Multivariate models of HIV/AIDS knowledge, 2002 Cape Area Panel Study $(\mathrm{n}=4,174)$

\begin{tabular}{|c|c|c|c|c|c|c|c|c|c|}
\hline & \multicolumn{3}{|c|}{ Always use condoms } & \multicolumn{3}{|c|}{ Abstain from sex } & \multicolumn{3}{|c|}{ Limit sex partners / monogamy } \\
\hline & Odds ratio & Std. err. & $\mathrm{P}$ & Odds ratio & Std. err. & $\mathrm{p}$ & Odds ratio & Std. err. & $\mathrm{p}$ \\
\hline Age & 0.916 & 0.043 & 0.064 & 0.971 & 0.028 & 0.318 & 1.084 & 0.033 & 0.008 \\
\hline Male & 1.131 & 0.137 & 0.312 & 0.825 & 0.063 & 0.012 & 0.770 & 0.072 & 0.006 \\
\hline Coloured & 0.324 & 0.204 & 0.074 & 0.957 & 0.391 & 0.914 & 6.612 & 2.349 & 0.000 \\
\hline White & 0.037 & 0.033 & 0.000 & 0.329 & 0.209 & 0.081 & 21.206 & 13.985 & 0.000 \\
\hline Currently in school & 0.720 & 0.138 & 0.086 & 1.416 & 0.140 & 0.001 & 1.147 & 0.131 & 0.233 \\
\hline In school x coloured & - & - & - & - & - & - & - & - & - \\
\hline In school $x$ white & - & - & - & - & - & - & - & - & - \\
\hline Highest grade completed & 0.994 & 0.055 & 0.918 & 1.235 & 0.044 & 0.000 & 1.086 & 0.035 & 0.011 \\
\hline Highest grade $\mathrm{x}$ coloured & 1.107 & 0.075 & 0.135 & 1.043 & 0.046 & 0.334 & 0.871 & 0.033 & 0.000 \\
\hline Highest grade $\mathrm{x}$ white & 1.348 & 0.119 & 0.001 & 1.154 & 0.075 & 0.028 & 0.817 & 0.050 & 0.001 \\
\hline Ever had sex & 2.777 & 0.427 & 0.000 & 0.562 & 0.076 & 0.000 & 1.407 & 0.167 & 0.004 \\
\hline Ever had sex x coloured & - & - & - & 0.757 & 0.138 & 0.128 & - & - & - \\
\hline Ever had sex x white & - & - & - & 0.537 & 0.161 & 0.038 & - & - & - \\
\hline $\begin{array}{l}\text { Know somebody with or } \\
\text { who died of HIV/AIDS }\end{array}$ & 1.220 & 0.197 & 0.218 & 1.058 & 0.099 & 0.548 & 1.391 & 0.191 & 0.017 \\
\hline $\begin{array}{l}\text { Know somebody with/died } \\
\text { of HIV x coloured }\end{array}$ & - & - & - & - & - & - & 0.690 & 0.132 & 0.053 \\
\hline $\begin{array}{l}\text { Know somebody with/died } \\
\text { of HIV } x \text { white }\end{array}$ & - & - & - & - & - & - & 0.742 & 0.230 & 0.335 \\
\hline F & 8.47 & & & 20.50 & & & 8.54 & & \\
\hline $\mathrm{p}$ & 0.000 & & & 0.000 & & & 0.000 & & \\
\hline
\end{tabular}


J. Social Sci., 3 (3): 143-150, 2007

Table 2: (continued)

\begin{tabular}{|c|c|c|c|c|c|c|}
\hline & \multicolumn{3}{|c|}{ Use sterilised needles } & \multicolumn{3}{|c|}{ Number of ways to prevent HIV/AIDS } \\
\hline & Odds ratio & Std. err. & $\mathrm{P}$ & Coeff. & Std. err. & $p$ \\
\hline Age & 0.824 & 0.048 & 0.001 & -0.013 & 0.011 & 0.245 \\
\hline Male & 0.868 & 0.118 & 0.301 & -0.068 & 0.034 & 0.047 \\
\hline Coloured & 4.224 & 1.304 & 0.000 & 0.145 & 0.146 & 0.322 \\
\hline White & 7.989 & 2.787 & 0.000 & -0.219 & 0.404 & 0.588 \\
\hline Currently in school & 0.967 & 0.176 & 0.855 & 0.010 & 0.043 & 0.820 \\
\hline In school x coloured & - & - & - & 0.122 & 0.055 & 0.029 \\
\hline $\begin{array}{l}\text { In school } x \text { white } \\
\text { Hiohest orade }\end{array}$ & - & - & - & 0.206 & 0.170 & 0.227 \\
\hline $\begin{array}{l}\text { completed } \\
\text { Highest grade x }\end{array}$ & 1.243 & 0.068 & 0.000 & 0.068 & 0.010 & 0.000 \\
\hline coloured & - & - & - & 0.007 & 0.014 & 0.610 \\
\hline Highest grade $\mathrm{x}$ white & - & - & - & 0.066 & 0.033 & 0.049 \\
\hline Ever had sex & 0.243 & 0.094 & 0.000 & -0.060 & 0.047 & 0.202 \\
\hline Ever had sex x coloured & 4.342 & 1.846 & 0.001 & - & - & - \\
\hline Ever had sex x white & 4.080 & 1.955 & 0.004 & - & - & - \\
\hline $\begin{array}{l}\text { Know somebody with or } \\
\text { who died of HIV/AIDS }\end{array}$ & 2.531 & 0.776 & 0.003 & 0.052 & 0.034 & 0.122 \\
\hline $\begin{array}{l}\text { Know somebody } \\
\text { with/died of HIV x } \\
\text { coloured }\end{array}$ & 0.451 & 0.160 & 0.025 & - & - & - \\
\hline $\begin{array}{l}\text { Know somebody } \\
\text { with/died of HIV x } \\
\text { white }\end{array}$ & 0.168 & 0.082 & 0.000 & - & - & - \\
\hline $\mathrm{F}$ & 11.83 & & & 24.30 & & \\
\hline$p$ & 0.000 & & & 0.000 & & \\
\hline
\end{tabular}

On average, respondents could name 1.9 ways to prevent HIV infection. Virtually everyone $\mathbf{9 9 . 4 \%}$ of respondents) could name at least one method of prevention, with $60.5 \%$ of respondents able to name more than one (not shown in the table). The average number of methods mentioned was highest for whites (2.3) and lowest for blacks (1.5), with coloureds in between (1.9). Always using condoms was the most commonly reported way to protect oneself from HIV/AIDS, mentioned by $89 \%$ of respondents. This is the only prevention method that blacks named more frequently than the other groups. Abstaining from sex was the second most commonly named prevention method, and was the only other method named by a near majority of respondents (46.5\%). Limiting the number of sex partners or having only one sex partner was the next most commonly named prevention method, mentioned by nearly a quarter of respondents (22.3\%). The fourth most commonly named prevention method, using sterilised needles, was mentioned by only $11 \%$ of respondents. Other prevention methods were mentioned by less than $10 \%$ of respondents. Apart from using condoms, each prevention method was named most frequently by whites and least frequently by blacks.

Table 2 presents multivariate regression models of the four most commonly named ways to prevent HIV infection, as well as the cumulative number of ways to prevent infection named by each respondent. Both main effects and interaction effects are shown in the table. With respect to main effects, no variable is significant across all models, but most are significant in two or more models. Results for the background variables (age, gender, and race) indicate older youth have lower odds of mentioning condom use or sterilised needles (although the effect of age on condom use is only marginally significant) and higher odds of mentioning limiting the number of sex partners or having only one sex partner (i.e., monogamy). Males are less likely than females to mention abstinence or limiting the number of sex partners, and they also name fewer methods of prevention. Coloureds and whites are less likely than blacks to mention condom usage (although this effect is only marginally significant for coloureds). In addition, coloureds and whites are significantly more likely than blacks to mention limiting the number of sex partners/monogamy or sterilised needles. Whites also have marginally lower odds of mentioning abstinence relative to blacks. There are no main effects of race on the number of prevention methods named.

The results indicate important associations between schooling and HIV/AIDS prevention knowledge. School enrollment is significant for two outcomes. Youth who are currently enrolled in school 
are less likely to name condoms (although this effect is only marginally significant) and more likely to name abstinence. School enrollment $x$ coloured is significant for the number of ways named to prevent HIV infection, suggesting that school enrollment has a more positive association with the number of prevention methods named for coloureds (relative to blacks). Higher grade attainment is positively associated with naming abstinence, limiting sex partners/monogamy, sterilised needles, and more prevention methods. Interactions between race and highest grade completed are significant in four models. For condom use, abstinence, and number of prevention methods mentioned, highest grade $\mathrm{x}$ white is significant, indicating that higher grade attainment is associated with higher levels of these outcomes for whites. (The interaction terms for coloureds are not significant in these models.) For limiting sex partners/monogamy, the interaction terms between highest grade and both coloureds and whites are significant and less than one, suggesting that grade attainment is associated with lower odds of mentioning this prevention method for both coloureds and whites relative to blacks.

Sexual experience (i.e., having ever had sex) is a significant correlate of HIV/AIDS prevention knowledge. Sexually experienced youth have higher odds of mentioning condoms or limiting the number of partners, and lower odds of mentioning abstinence or sterilised needles. Interactions between race and having ever had sex are significant for two models. For both blacks (indicated by the main effect) and whites (indicated by ever had sex $\mathrm{x}$ white), but not for coloureds, youth who have had sex are less likely to mention abstinence as a form of HIV/AIDS protection. For sterilised needles, the significant interaction terms indicate that coloureds and whites who have had sex are more likely to mention sterilised needles as a form of HIV/AIDS prevention relative to blacks.

Finally, the main effect of knowing somebody with or who died of HIV/AIDS (i.e., personal experience with HIV/AIDS) is associated with a greater likelihood of mentioning limiting partners/monogamy or sterilised needles. The interaction term for coloureds and personal experience is marginally significant in the model of limiting sex partners/monogamy, indicating that for coloureds, knowing somebody with or who died of HIV/AIDS is associated with lower odds of mentioning that method. Personal experience with HIV/AIDS is also associated with lower odds of mentioning sterilised needles for both coloureds and whites relative to blacks.

\section{DISCUSSION}

We examined the level and correlates of HIV/AIDS prevention knowledge among youth in Cape Town, South Africa. In contrast to some studies of the
HIV/AIDS knowledge of youth in Africa, we used a multi-racial, representative sample of youth and an open-ended measure of HIV/AIDS prevention knowledge. Our findings show that the vast majority of youth in Cape Town have at least some knowledge about HIV/AIDS prevention, but the results also reveal important gaps in HIV/AIDS prevention knowledge. While nearly everybody in the sample knew that HIV infection is preventable, most respondents could name only two ways to prevent HIV infection.

We found marked variation in the HIV/AIDS prevention methods that respondents could name. The most frequently mentioned prevention methods were, in order, condom use (mentioned by $88 \%$ of respondents), abstinence (47\%), and limiting the number of sexual partners/monogamy (23\%). These results are consistent with those of other South African studies that have used open-ended questions to assess young people's HIV/AIDS prevention knowledge ${ }^{\{14,15,27]}$. Taken together, the findings from these studies indicate that the ABC campaign (Abstain, Be faithful, use a Condom) has been most successful in teaching youth about the importance of condoms, but more efforts may be needed to educate youth about the importance of abstinence and monogamy or limiting the number of sexual partners, as well as other methods (e.g., using sterilised needles) for preventing HIV/AIDS. Overall, our results indicate more depth of knowledge about HIV/AIDS prevention is needed in South Africa to ensure proper protection from the disease.

Our predictions about the correlates of HIV/AIDS prevention knowledge were supported to varying degrees. Age was positively associated with only one measure of HIV/AIDS knowledge, limiting sex partners/monogamy. Males were generally less knowledgeable about HIV/AIDS prevention than females. School enrollment was positively associated with naming abstinence. Grade attainment was positively associated with the total number of prevention methods mentioned and with the odds of mentioning several specific methods. Individuals who knew someone living with or who has died from HIV/AIDS were more likely to mention two specific prevention methods, limiting sex partners/monogamy and sterilised needles.

HIV/AIDS risk behaviour had a more ambiguous relationship with HIV/AIDS prevention knowledge in our study. Youth who have had sex were more likely to mention using condoms or limiting the number of sex partners, but were less likely to mention abstinence or sterilised needles. The causal relationship between having sex and HIV/AIDS knowledge (i.e., whether knowledge precedes or follows sexual experience) is unclear from our data. In particular, whether sexually experienced youth do not know that abstinence reduces the risk of HIV infection, or whether they choose to ignore such an inconvenient truth, deserves further exploration. 
Main effects of racial group were apparent in most models. Blacks were generally less likely than coloureds or whites to name a particular prevention method, with the exception that blacks were the most likely to mention condoms as a form of HIV/AIDS prevention. There were no racial differences in the total number of prevention methods once other factors were controlled; this lack of racial differences is likely due to the fact that although blacks were less likely to mention most methods, they were much more likely to mention condoms. Additionally, interaction terms with race were significant in many models, suggesting the relationships between key correlates and HIV/AIDS prevention knowledge vary by race. School enrollment, grade attainment, and sexual experience were generally associated with greater HIV/AIDS prevention knowledge for coloureds and/or whites relative to blacks. Future research should investigate why schooling and sexual experiences may be less important for HIV/AIDS knowledge among blacks. In contrast, knowing somebody with or who died of HIV/AIDS was associated with less HIV/AIDS prevention knowledge for coloureds and whites relative to blacks, suggesting personal experience with HIV/AIDS has a greater positive impact on HIV/AIDS knowledge for blacks than for other groups. This finding might reflect the greater impact of the HIV/AIDS epidemic on the black community in South Africa.

The significant main effects and interaction effects for race demonstrate the importance of race/ethnicity to HIV/AIDS prevention knowledge among South African youth. Race is a complex issue, especially in South Africa, and may represent a number of social and cultural factors including socioeconomic background, discrimination, access to information, beliefs about health and illness, and sexual norms. The ways in which individuals process information about HIV/AIDS through cultural filters may lead to different levels of HIV/AIDS knowledge across racial/ethnic groups. That HIV/AIDS-related research in southern Africa needs to pay more attention to social and cultural factors has been noted by others, and our findings underscore the importance of doing this ${ }^{[8,9,28]}$. While the continued use of racial group classifications in South Africa has been criticized, race may tap into real and practical differences in the way South African youth access and use information about HIV/AIDS, and this should be considered more carefully in future HIV/AIDS education programmes and research.

Numerous HIV/AIDS education and prevention programmes targeted at young people exist in South Africa. Most of these programmes have attempted to reach a wide range of individuals, and some programmes have been developed to target specific racial/ethnic groups ${ }^{[29]}$. In spite of these efforts, there are important racial differences in knowledge of HIV/AIDS prevention methods and how that knowledge is used. For example, black youth are more likely than others to know about condoms as a prevention method, but they tend to be less knowledgeable about other prevention methods. And even though knowledge about condoms is high among blacks, there may be cultural and practical barriers (e.g., low perceived risk of HIV infection, or differential access to condoms) that prevent blacks from using them ${ }^{[6,30]}$. Thus, more culturally sensitive prevention programmes may be needed that not only increase young people's knowledge about HIV/AIDS prevention but also assist them in acting upon that knowledge.

In conclusion, theoretical models predict that HIV/AIDS knowledge is an important factor influencing HIV/AIDS risk perceptions and risk behaviours. In a country with high HIV prevalence such as South Africa, understanding the factors influencing HIV/AIDS prevention knowledge has important policy implications. Our study underscores the importance of continuing to assess knowledge about HIV/AIDS among South African youth, and sheds new light on the importance of race to the process by which young people learn about HIV/AIDS and use that knowledge. Blacks have been disproportionately affected by the HIV/AIDS epidemic, and it is important that the legacy of apartheid not be allowed to create further health inequalities by race in contemporary South Africa. Beyond South Africa, our findings suggest that HIV/AIDS education and prevention programmes in high prevalence countries should pay particular attention to devising culturally sensitive ways to teach socially disadvantaged groups about HIV/AIDS knowledge and to empower them to act upon their HIV/AIDS knowledge.

\section{ACKNOWLEDGEMENTS}

The Cape Area Panel Study Waves 1-2-3 were collected between 2002 and 2005 by the University of Cape Town and the University of Michigan, with funding provided by the US National Institute for Child Health and Human Development and the Andrew W. Mellon Foundation.

\section{REFERENCES}

1. Catania, J., S. Kegeles and T. Coates, 1990. Toward an understanding of risk behavior: An AIDS risk reduction model (ARRM). Health Education Quarterly, 17: 53-72.

2. Fisher, J.D. and W.A. Fisher, 1992. Changing AIDS risk behavior. Psychological Bulletin, 111: 455-474.

3. Janz, N. and M. Becker, 1984. The health belief model: A decade later. Health Education Quarterly, 11: 1-47.

4. Shisana, O., T. Rehle, L.C. Simbayi, W. Parker, K. Zuma, A. Bhana, C. Connolly, S. Jooste and V. Pillay, 2005. South African National HIV Prevalence HIV Incidence, Behaviour and Communication Survey, 2005. HSRC Press, Cape Town, South Africa. 
5. UNAIDS. 2006. 2006 Report on the Global AIDS Epidemic. United Nations Publications, New York.

6. Eaton, L., A.J. Flisher and L.E. Aarø, 2003. Unsafe sexual behavior in South African youth. Social Science and Medicine, 56: 149-165.

7. Eaton, L. and A.J. Flisher, 2000. HIV/AIDS knowledge among South African youth. Southern African Journal of Child and Adolescent Mental Health, 12: 97-124.

8. MacPhail, C. and C. Campbell, 2001. "I think condoms are good but, aai, I hate those things": Condom use among adolescents and young people in a Southern African township. Social Science and Medicine, 52: 1613-1627.

9. Tillotson, J. and P. Maharaj, 2001. Barriers to HIV/AIDS protective behavior among African adolescent males in township secondary schools in Durban, South Africa. Society in Transition, 32: 83-100.

10. Barden-O’Fallon, J.L., J. de Graft-Johnson, T. Bisika, S. Sulzbach, A. Benson and A.O. Tsui, 2004. Factors associated with HIV/AIDS knowledge and risk perception in rural Malawi. AIDS and Behavior, 8: 131-140.

11. Slonim-Nevo, V. and L. Mukuka, 2005. AIDSrelated knowledge, attitudes and behavior among adolescents in Zambia. AIDS and Behavior, 9: 223-231.

12. Smith, D.J., 2004. Premarital sex, procreation, and HIV risk in Nigeria. Studies in Family Planning, 35: 223-235.

13. Terry, P.E., M. Mhloyi, T. Masvaure and S. Adlis, 2006. An examination of knowledge, attitudes and practices related to HIV/AIDS prevention in Zimbabwean university students: Comparing intervention program participants and nonparticipants. International Journal of Infectious Diseases, 10: 38-46.

14. Pettifor, A.E., H.V. Rees, A. Steffenson, L. HlongwaMadikizela, C. MacPhail and K. Vermaak, 2004. HIV and sexual behaviour among young South Africans: A national survey of 15-24 year olds. Reproductive Health Research Unit, University of Witwatersrand, Johannesburg, South Africa.

15. Zambuko, O. and A.J. Mturi, 2005. Sexual risk behaviour among the youth in the era of HIV/AIDS in South Africa. Journal of Biosocial Science, 37: 569-584.

16. Maswanya, E.S., K. Moji, I. Horiguchi, K. Nagata, K. Aoyagi and S. Honda, 1999. Knowledge, risk perception of AIDS and reported sexual behavior among students in secondary schools and colleges in Tanzania. Health Education Research, 14: 185-196.

17. Magnani, R.J., A. Karim, L. Weiss, K. Bond, M. Lemba and G. Morgan, 2002. Reproductive health risk and protective factors among youth in Lusaka, Zambia. Journal of Adolescent Health, 30: 76-86.

18. Peltzer, K. and S. Promtussananon, 2003. Evaluation of Soul City school and mass media life skills education among junior secondary school learners in South Africa. Social Behavior and Personality, 31: 825-834.
19. Pettifor, A.E., H.V. Rees, I. Kleinschmidt, A.E. Steffenson, C. MacPhail, and L. HlongwaMadikizela, 2005. Young people's sexual health in South Africa: HIV prevalence and sexual behaviours from a nationally representative household survey. AIDS, 19: 1525-1534.

20. Simbayi, L.C., J. Chauveau and O. Shisana, 2004. Behavioural responses of South African youth to the HIV/AIDS epidemic: A nationwide survey. AIDS Care, 16: 605-618.

21. Boer, H. and M.T. Mashamba, 2005. Psychosocial correlates of HIV protection motivation among black adolescents in Venda, South Africa. AIDS Education and Prevention, 17: 590-602.

22. Peltzer, K. and S. Promtussananon, 2005. HIV/AIDS knowledge and sexual behavior among junior secondary school students in South Africa. Journal of Social Sciences, 1: 1-8.

23. Burgard, S.A. and D.J. Treiman, 2006. Trends and racial differences in infant mortality in South Africa. Social Science and Medicine, 62: 11261137.

24. Charasee-Pouélé, C. and M. Fournier, 2006. Health disparities between racial groups in South Africa: A decomposition analysis. Social Science and Medicine, 62: 2897-2914.

25. Peltzer, K., L. Cherian and V.I. Cherian, 2000. Knowledge, self-efficacy and behavioral intent towards AIDS prevention behaviours among culturally diverse secondary school pupils in South Africa. East African Medical Journal, 77: 279-282.

26. Lam, D. and J. Seekings, 2005. The Cape Area Panel Study (CAPS): Technical documentation for wave 1 (2002). Centre for Social Science Research, University of Cape Town, South Africa.

27. Varga, C. and L. Makubalo, 1996. Sexual nonnegotiation. Agenda, 28: 31-38.

28. Schatz, P. and K.P. Dzvimbo, 2001. The adolescent sexual world and AIDS prevention: A democratic approach to programme design in Zimbabwe. Health Promotion International, 16: 127-136.

29. James, S., P.S. Reddy, R.A.C. Ruiter, M. Taylor, C.C. Jinabhai, P. Van Empelen and B. Van Den Borne, 2005. The effects of a systematically developed photo-novella on knowledge, attitudes, communication and behavioral intentions with respect to sexually transmitted infections among secondary school learners in South Africa. Health Promotion International, 20: 157-165.

30. Maharaj, P., 2006. Reasons for condom use among young people in KwaZulu-Natal: Prevention of HIV, pregnancy or both? International Family Planning Perspectives, 32: 28-34. 